\title{
Risk analysis for occurrences of schistosomiasis in the coastal area of Porto de Galinhas, Pernambuco, Brazil
}

Elainne Christine de Souza Gomes ${ }^{1 *}$, Onicio Batista Leal-Neto², Fernando José Moreira de Oliveira $\mathrm{Jr}^{3}$, Julyana Viegas Campos ${ }^{2}$, Reinaldo Souza-Santos ${ }^{4}$ and Constança Simões Barbosa ${ }^{2}$

\begin{abstract}
Background: Manson's schistosomiasis continues to be a severe public health problem in Brazil, where thousands of people live under the risk of contracting this parasitosis. In the Northeast of Brazil, schistosomiasis has expanded from rural areas to the coast of Pernambuco State, where the intermediate host is Biomphalaria glabrata snails. This study aims at presenting situational analyses on schistosomiasis at the coastal locality of Porto de Galinhas, Pernambuco, Brazil, by determining the risk factors relating to its occurrence from the epidemiological and spatial perspectives.
\end{abstract}

Methods: In order to gather prevalence data, a parasitological census surveys were conducted in 2010 in the light of the Kato-Katz technique. Furthermore, malacological surveys were also conducted in the same years so as to define the density and infection rates of the intermediate host. Lastly, socioeconomic-behavioral survey was also conducted to determine the odds ratio for infection by Schistosoma mansoni. Based on these data, spatial analyses were done, resulting in maps of the risk of disease transmission. To predict the risk of schistosomiasis occurrence, a multivariate logistic regression was performed using R 2.13 software.

Results: Based on prevalence, malacological and socioeconomic-behavioural surveys, it was identified a prevalence of $15.7 \%$ in the investigated population (2,757 individuals). Due to the malacological survey, 36 breeding sites were identified, of which 11 were classified as foci of schistosomiasis transmission since they pointed out snails which were infected by Schistosoma mansoni. Overall, 11,012 snails (Biomphalaria glabrata) were collected. The multivariate regression model identified six explanatory variables of environmental, socioeconomic and demographic nature. Spatial sweep analysis by means of the Bernoulli method identified one statistically significant cluster in Salinas $(R R=2.2 ; p$-value $<0.000)$, the district with the highest occurrence of cases.

Conclusions: Based on the resulting information from this study, the epidemiological dimensions of this disease are significant and severe, within the scenario of schistosomiasis in Pernambuco state. The risk factors which were identified in the predictive model made it clear that the environmental and social conditions influence on the schistosomiasis occurrences.

Keywords: Schistosomiasis, Risk analysis, Spatial analysis, Pernambuco, Brazil

\footnotetext{
* Correspondence: elainnechristine@hotmail.com

'Laboratory of Parasitology, Vitoria Academic Center, Federal University of Pernambuco, Recife, Pernambuco, Brazil

Full list of author information is available at the end of the article
} 


\section{Background}

Occurrences of schistosomiasis, which is an endemic disease in several countries, are modulated not only by the biological components of the snail that is its vector and definitive host of Schistosoma mansoni but also by complex social and cultural processes related to human behaviour and disorderly occupation of urban spaces [1-3]. It has been perceived the importance of socioeconomic characteristics and human behaviour regarding water contact and sanitation condition, as these factors are directly related to the frequency and intensity of human exposure to transmission foci of this disease [4]. The degree of relationship between these factors could determine the risk and transmission rates in localities where the disease became established [5].

The study of patterns of contact with the use of water at breeding sites for Biomphalaria on the coast of the state of Pernambuco showed that the rainy season conditioned contact and involuntary exposure to that vector, insofar as $92 \%$ of the surveyed individuals said that they had not had any contact with contaminated water during the dry season, whilst $46 \%$ also reported that they had been in contact with natural breeding sites when they overflowed at the time of the rains, causing exposure and contamination inside their own homes [6]. Lack of sanitation was highlighted as a socioeconomic determinant for schistosomiasis, inasmuch as this allowed faecal contamination of water accumulations and promoted the beginning of the disease transmission cycle [7]. On the periphery of urban localities, organic sediments originated by used water and open-air sewage not only provided a source of nourishment to the molluscs but also maintained the peridomestic foci of vectors and ensured schistosomiasis transmission [8].

The socioeconomic profile was also indicated as a determinant for occurrences of the disease. Low schooling levels among the heads of families, the amount of people per habitation as well as poor financial conditions among those families are considered to be risk factors to incur schistosomiasis $[9,10]$. The conjoint analysis of these factors could be able to establish a risk value that could also be expressed as a "risk ratio" by means of regression analysis [7,9]. In this manner, an attempt can be made to understand the schistosomiasis transmission process in an ecological and dynamic way.

Within this perspective, spatial analysis on health events has proved to be a valuable tool for epidemiological studies, as it enables information to be aggregated, health indicators to be established, landscapes to be characterized, and categorizing schistosomiasis occurrences to be modulated. Details of the environmental conditions that interfere in the population's health can be illustrated on maps that present the spatial distribution of areas at risk, thus it makes it possible for epidemiologists to understand the dynamics of the disease, along with its variations in space and time. For spatial analysis on socioeconomic, behavioural, biological and environmental risk factors, physical and topographic maps of the studied localities, in digital format, need to be used [11]. These should contain geographical features such as: blocks, plots, constructions, water accumulations, relief and vegetation, and they should be used jointly with geodesic coordinates which could be provided by the global positioning system (GPS) and spatial statistical software [12].

Spatial statistical analysis has been used as a tool for predicting occurrences of schistosomiasis in studies conducted in the Philippines and the Caribbean $[13,14]$ and widely used in studies on this health hazard as it has produced inferences regarding associations between infection and environmental variables. Field studies and modelling have improved the understanding of the spatial epidemiology of schistosomiasis in Africa, and have shown its relevance in planning schistosomiasis control programmes $[5,15]$.

Data on points of occurrence of an event can be analysed based on identifying spatial agglomerations known as 'clusters'. Some of those clusters analyses provide geostatistical parameters, such as the relative risk for some areas identified by the cluster and p-value as it is illustrated in Bernoulli's method [16]. This technique has been used in several fields of studies to detect the spatial risk of disease occurrence [16-19]. Areas at risk can also be estimated empirically, based on knowledge of the territorial extent, by creating 'buffers' which are consisted of risk bands, from identified areas of influence for those variables. This type of analysis enables better spatial understanding of the transmission and occurrence of a disease.

Concerning schistosomiasis, Brazil is considered the most affected country in the Americas. It has been estimated that around 30 million people are exposed to the risk of contracting this disease [20,21], and its prevalence may have already surpassed eight million individuals [22]. Moreover, for over a decade, schistosomiasis has been ceasing to be a characteristically rural endemic disease and has been expanding into urban and coastal areas of Brazil, and by such it has been exposing a new portion of the population to the risk of becoming infected [1,2,23-27].

Within this perspective, the present study aims at presenting the results from a situational analysis on schistosomiasis and determining the extent of the epidemiological and spatial risks of this disease at the coastal locality of Porto de Galinhas, Pernambuco, Brazil.

\section{Methods}

\section{Study area}

This study was developed at the locality of Porto de Galinhas, in the municipality of Ipojuca, on the southern 
coast of the state of Pernambuco, at a distance of $60 \mathrm{~km}$ from the state capital city, Recife (Figure 1). This locality was chosen in view of records of breeding sites for B. glabrata and a high number of cases that have been registered over the last decade [28]. For the malacological survey and schistosomiasis investigation, the entire area of Porto de Galinhas was taken into consideration (videlicet: Merepe I, II and III; Salinas, Socó, Pantanal and Vila de Porto).

\section{Data gathering and analysis Mapping of the locality}

Georeferenced mapping of the locality was performed in May and June 2010, using a GPS receiver (Garmin, model Vista Cx) configured in the UTM (Universal Transverse Mercator) projection system with the SAD 69 datum. The mapping included streets, main buildings and water accumulations containing the vector mollusc, and the latter were subsequently classified as breeding sites or foci of schistosomiasis transmission. After the human prevalence survey on schistosomiasis had been taken, all the residences in which at least one individual had undergone a parasitological faeces examination (with both positive and negative results for schistosomiasis) were also georeferenced.

For all the spatial analyses on the data, only the localities of Merepe III, Salinas, Socó and Pantanal were taken into consideration. These were the areas in which more than $70 \%$ of the permanent population of Porto de Galinhas were living, as it was informed by the Municipal Health Department (Figure 1).

\section{Malacological survey}

Snails were collected at demarcated stations at the breeding sites that had been identified, in random sampling every month over a one-year period (from July 2010 to June 2011). In each station the snails were caught by using scoops and tweezers during every15-minute periods, and stored properly in moistened and ventilated plastic jars, which were also labelled according to the number of the corresponding breeding site. Then, they were taken to the Schistosomiasis Laboratory and Reference Service at the Aggeu Magalhães Research Center Fiocruz, in order to be examined. To diagnose infection

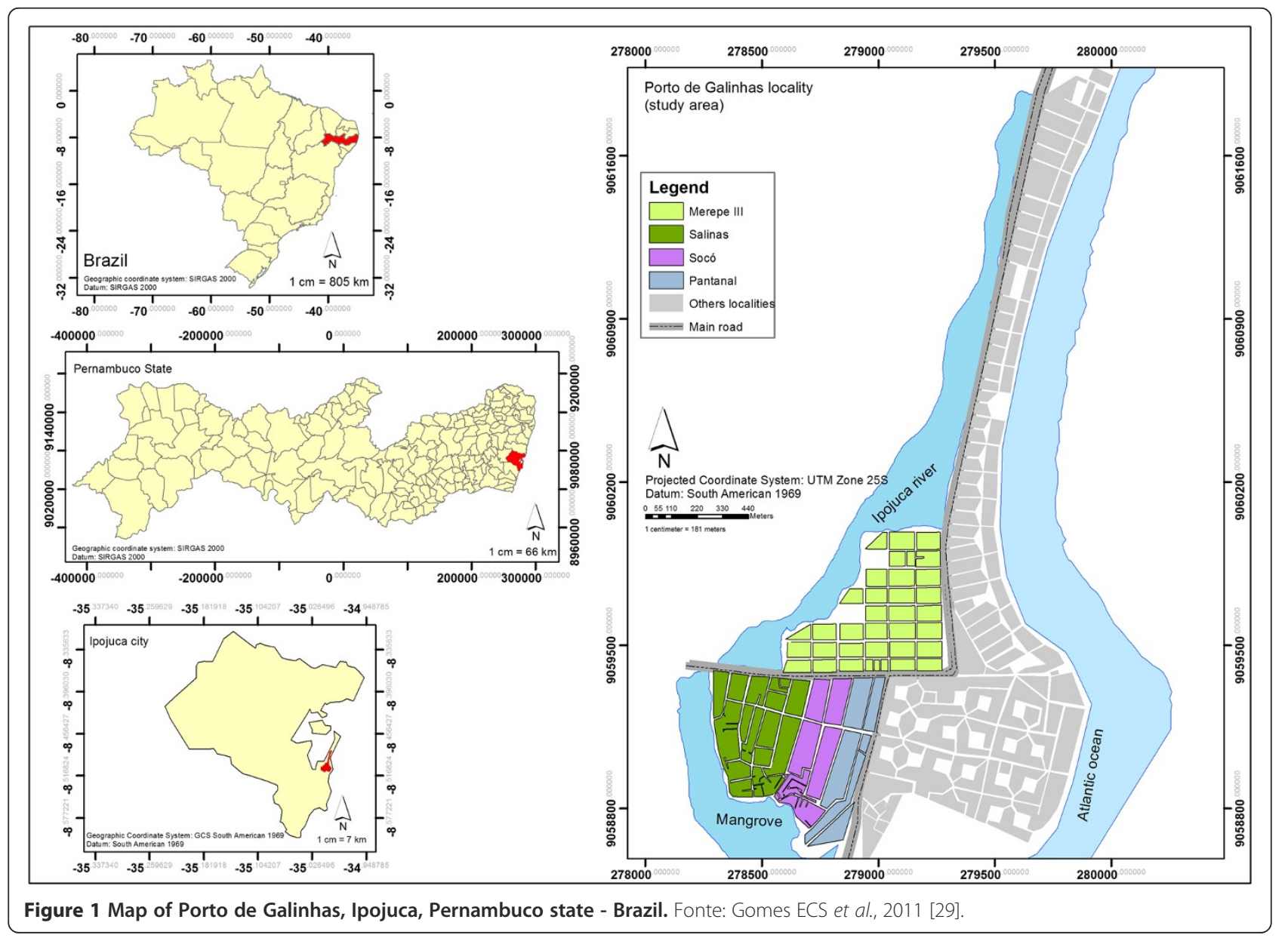


and identify transmission foci (i.e. breeding sites in which snails infected with S. mansoni were found), the snails were exposed to artificial light so that the cercariae would be expelled [30]. Snails that were found to be negative were re-examined using the same technique 15 days after the first examination. Those that continued to be negative were then crushed, in groups of 12 , on glass plates whose dimensions were $15 \times 9 \mathrm{~cm}$, and then they were examined individually under a stereoscopic microscope in search of sporocysts (larval stages) of $S$. mansoni [31]. The snail density per breeding site was defined according to the absolute number of snails collected in each breeding site per month. To determine the natural infection rate or infectivity rate, it was calculated the proportion of the molluscs that were positive for $S$. mansoni in relation to the total number of molluscs examined. In this manner, the monthly and annual infection rates were calculated for each breeding site and transmission focus, in order to estimate the potential for infectivity and disease transmission at each focus.

\section{Prevalence survey}

Between August and December 2010, a coproscopic census survey was conducted based on voluntary registration and participation of individuals living in Porto de Galinhas. After signing the consent form provided by the ethics committee from Aggeu Magalhães Research Center - who approved the whole study, it was given to them a plastic container to collect stool sample, which could be identified by the name of each participant that agreed in taking part of this research. Thus, stool samples were collected and sent to the laboratory in order to be examined.

To define the number of cases of schistosomiasis and the parasite load in these individuals, parasitological examinations were conducted on their faeces by means of the Kato-Katz method [32], with one sample from each patient, from which two slides were examined. The prevalence of schistosomiasis in Porto de Galinhas was defined from the results of the parasitological faeces examinations, using the following formula: total number of positive individuals/ total number of individuals examined $\times 100$. The human infection rate or parasite load of each individual was defined by multiplying the number of eggs found on each slide by the constant 24, in order to obtain the number of eggs per gram of faeces (EPG). Since two slides were made from each sample, the result related to the parasite load for each individual was formed by the arithmetic mean of the EPG from the two slides examined.

\section{Risk analysis}

In March 2011, sanitary, environmental, socioeconomic and behavioural data were gathered by means of a questionnaire which was applied to all the individuals who participated in the study and were available to answer the questions. The demographic data related to age and sex were obtained from the coproscopic survey forms that had been filled out by the time of registering of these individuals.

With the aim of creating a model that would enable predictions of the risk of schistosomiasis occurrence, multivariate logistic regression was performed in $R$ software. The dependent variable was taken to be the occurrence of the case $(0=$ non-case; $1=$ case), and the independent or explanatory variables were taken to be the environmental, social, economic and behavioural data that had been gathered by means of the socioenvironmental questionnaire, along with the demographic data of age (age group) and sex. These independent variables were categorized as zero for protection factors and one for risk factors, with the exception of age, which risk factor was stratified as 1,2 or 3 . Thus, the following categories were set up: home with piped water (0), home without piped water (1); home in which no water was accumulated in the backyard in winter (0), home with accumulated water in the backyard in winter (1); home in which no water was accumulated in the backyard in summer (0), home with accumulated water in the backyard in summer (1); sewage disposal into the 'general sewage system' (0), sewage disposal into 'septic pit or open ditch' (1); schooling level of the head of the family: 'high school or university level' (0), 'illiterate or elementary education level' (1); age group: '0 - 9 years old or > 60 years old' (0), ' 10 - 19 years old' (1), '20 - 39 years old' (2), '40 - 60 years old' (3); number of members of the family per home: '< 5 people' $(0)$, ‘ $\geq 5$ people' ( 1 ); not stepping in water when going out from home in winter $(0)$, stepping in water when going out from home in winter (1); not stepping in water when going out from home in summer (0), stepping in water when going out from home in summer (1); living in an asphalted street (0), not living in an asphalted street (1); family income '> 1 minimum monthly salary' (0), ' $\leq 1$ minimum monthly salary' (1); sex 'female' (0), 'male' (1); length of time living at the locality '< 1 year' $(0)$, '> 1 year' $(1)$.

Univariate models were run with the dependent variable and each of the independent variables, and the regressions that presented $\mathrm{p}$-values less than or equal to 0.25 were selected for the multivariate model. After forming the multivariate logistic model, the stepwise forward model was applied and the variables that presented p-values less than 0.05 were accepted to make up the final model. The chosen model was justified as the model that presented the lowest value for the Akaike Information Criterion (AIC) and the equation that best explained the problem.

\section{Spatial risk}

To establish the potential risk that a breeding site for B. glabrata would become a focus for schistosomiasis 
transmission, a thematic map demonstrating the occurrences of these breeding sites and foci was made in the form of kernel map of parasite load in human cases per home (over a radius of 200 meters [33]). Based on the distribution of the foci, a multiple ring buffer map was compiled, with pre-established distances of 50 meters (radius of a block), in order to estimate the expansion of the foci during rainy periods. Both analyses were performed using the ArcGis 10 software - Spatial Analysis Extension.

A sweep analysis was also performed to identify areas at greater risk of occurrences of cases (clusters), by using the geolocation of cases and non-cases. For this, the SaTScan 9.1.1 software was a useful tool and Bernoulli's method was used as well, such that the variables of "case" and "non-case" were dichotomous [18]. Based on that method, it is possible to identify clusters containing geostatistical representations, such as the relative risk, radius of the area at risk, and p-value. The clusters were obtained and the risk was determined through comparing the "number of observed cases" with the "number of expected cases". The significance test was based on the likelihood test, in which the p-value was obtained by means of the Monte Carlo test. Only the clusters with p-values $<0.05$ were considered in the results. Based on the results from this analysis, maps presenting areas at greater risk of occurrences of cases were designed, and these were correlated with the socioenvironmental information that had been gathered previously and were overlain with a satellite image of the area, by means of the ArcGis 10 software - Spatial Analysis Extension. These images were generated through panchromatic (PAN) and multispectral (MS) sensors on board of the QuickBird satellite, with spatial resolution of 0.6 (August, 2006) and 0.5 meters (June, 2010).

\section{Results}

Over the course of one year of malacological surveys, 11,012 snails of the species B. glabrata were collected from 36 breeding sites (I.R. 2.6\%) that were identified at the studied locality. Of these, 11 sites (representing $30.5 \%$ of the total breeding sites) were classified as foci of schistosomiasis transmission because they presented snails infected with S. mansoni. Thus, there were 272 positive snails in total. The spatial distribution of the breeding sites and schistosomiasis foci per district within the studied area, along with the respective population densities and infection rates of the snails, can be seen in Figure 2. Merepe III presented six breeding sites, of which one was a focus of transmission; Salinas was the district with the largest numbers of breeding sites and foci: 27 and 10, respectively; Socó and Pantanal only had three breeding sites between them. The foci with the highest snail infection rates were breeding site 7 (23.4\%) and 15 (49.1\%), which were the closest sites to the flooded mangrove swamp area. It was also observed that, although the infection rates were mostly low, there were high densities of snails at the foci and a large number of snails were collected over the complete year of investigation.

For the epidemiological census survey, 5,607 individuals were registered. Of these, 2,757 adhered to the investigation by returning with the biological samples (faeces) for the parasitological diagnoses. Of these, 434 were positive for S. mansoni. The prevalence of schistosomiasis in Porto de Galinhas was $15.7 \%$. The district with the most significant number of cases was Salinas, followed by Sóco and Pantanal. Merepe III and Vila de Porto that were the localities with least occurrence of cases, and as such, they presented the lowest prevalence rates (Table 1). The localities Merepe I and II are not represented in this table because their populations' adherence to the survey was low, insomuch as only 57 individuals were examined, of whom nine were cases of the disease.

To determine the risk factors relating to occurrences of schistosomiasis at the study localities, 549 questionnaires were applied at the homes that formed part of the sample, which represented $60.3 \%$ of the totality. These questionnaires delineated the socioeconomic, behavioural and sanitary-environmental profile of 1,719 individuals (62.3\% of the total population samples) representing 1,429 "non-cases" (61.5\% of the non-cases) and 290 'cases' (66.8\% of the cases). With the objective of identifying the risk factors for occurrences of schistosomiasis, all the variables presented in Table 2 were included in a logistic regression analysis, which identified the eight explanatory variables shown in Table 3.

The first explanatory variable for occurrences of schistosomiasis cases in Porto de Galinhas was 'the accumulation of water in the backyard in winter'. Table 2 shows that $70 \%$ of the cases presented this condition. According to the regression model (Table 3), these cases represented a $40 \%$ greater risk of contracting schistosomiasis in comparison with the individuals without this condition. This explanatory variable is extremely important, whereas during the rainy season breeding sites were observed not only in the streets but also in the backyards and even inside homes. 'Low schooling level of the head of the family' was also a risk factor for occurrences of schistosomiasis, and around $90 \%$ of the individuals who were positive for schistosomiasis presented this condition (Table 2). The individuals exposed to this condition were at $60 \%$ greater risk of acquiring the disease (Table 3 ).

Age group was the variable that presented the highest risk that an individual would become a 'case'. This risk was twice as high for the age groups between 10 and 59 years, in comparison with the reference age group. However, attention was drawn to the young adult age group (20-39 years), which alone accounted for almost 


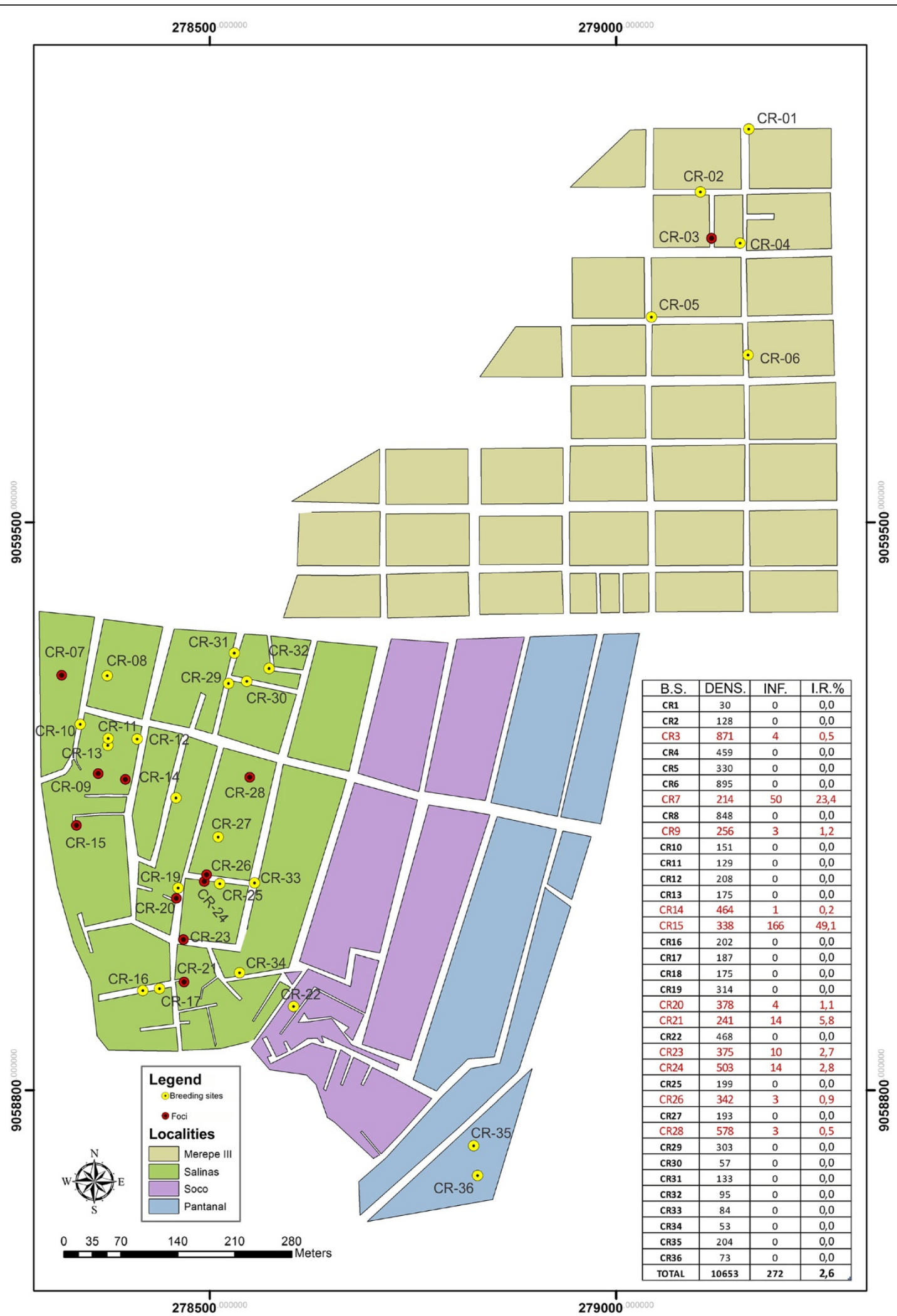

Figure 2 Spatial distribution of breeding sites and foci of B. glabrata in Porto de Galinhas, Ipojuca, Pernambuco - Brazil. 
Table 1 Occurrences of schistosomiasis cases and prevalence according to district, Porto de Galinhas, Ipojuca, Pernambuco, 2010

\begin{tabular}{|c|c|c|c|c|c|}
\hline \multirow[t]{2}{*}{ Districts } & \multirow[t]{2}{*}{ Sampled $(n)$} & \multicolumn{3}{|c|}{ Positives } & \multirow[t]{2}{*}{$95 \% \mathrm{Cl}$} \\
\hline & & No & $\%$ & Prevalence (\%) & \\
\hline Merepe III & 315 & 14 & 3.2 & 4.4 & $1.8-5.5$ \\
\hline Salinas* & 1263 & 259 & 59.7 & $20.6^{*}$ & $54.9-64.3$ \\
\hline Socó* & 590 & 96 & 22.1 & $16.3^{*}$ & $18.4-26.4$ \\
\hline Pantanal* & 291 & 40 & 9.2 & $13.7^{*}$ & $6.7-12.4$ \\
\hline Vila de Porto & 241 & 16 & 3.7 & 6.6 & $2.2-6.0$ \\
\hline Total & 2700 & 425 & 97.9 & 15.7 & - \\
\hline
\end{tabular}

${ }^{*}$ Frequency variation statistically significant $(\mathrm{Cl})$. half of the schistosomiasis cases registered at this locality (Table 2). Thus, the individuals in this age group were at almost three times greater risk of acquiring schistosomiasis, compared with the individuals in the reference age group, as shown in the regression model.

The urban infrastructure was also considered to be a risk factor, regarding the 'paving of the streets'. Individuals who were living in non-asphalted streets were at $57 \%$ greater chance of becoming ill, and it should be noted that almost $80 \%$ of the cases occurred at unpaved localities (Table 2). Individuals living in homes in which the family income was less than one minimum monthly salary were at $46 \%$ greater chance of becoming ill, and males were at $70 \%$ greater chance of acquiring this parasitosis, in comparison with females.

Table 2 Socioeconomic, behavioural and environmental characteristics of the population sampled in Porto de Galinhas Ipojuca, Pernambuco 2010

\begin{tabular}{|c|c|c|c|c|c|c|}
\hline \multirow[t]{2}{*}{ Independent variables } & \multicolumn{3}{|c|}{ Cases } & \multicolumn{3}{|c|}{ Non-cases } \\
\hline & No & $\%$ & $95 \% \mathrm{Cl}$ & No & $\%$ & $95 \% \mathrm{Cl}$ \\
\hline With piped water & 286 & 98.6 & $96.5-99.6$ & 1.381 & 96.6 & $95.5-97.5$ \\
\hline Without piped water & 4 & 1.4 & $0.4-3.5$ & 48 & 3.4 & $2.5-4.5$ \\
\hline No accumulation of water in backyard in winter & 89 & 30.7 & $25.4-36.3$ & 591 & 41.4 & $38.8-44.0$ \\
\hline With accumulated water in backyard in winter & 201 & 69.3 & $63.7-74.6$ & 838 & 58.6 & $56.0-61.2$ \\
\hline No accumulation of water in backyard in summer & 206 & 71.0 & $65.4-76.2$ & 1.046 & 73.2 & $70.8-75.5$ \\
\hline With accumulated water in backyard in summer & 84 & 29.0 & $23.8-34.6$ & 383 & 26.8 & $24.5-29.2$ \\
\hline Sewage disposal: general system & 6 & 2.1 & $0.8-4.4$ & 51 & 3.6 & $2.7-4.7$ \\
\hline Sewage disposal: pit or open ditch & 284 & 97.9 & $95.6-99.2$ & 1.378 & 96.4 & $95.3-97.3$ \\
\hline Head of family's schooling: high school or university & 36 & 12.7 & $9.1-17.2$ & 321 & 22.9 & $20.7-25.2$ \\
\hline Head of family's schooling: illiterate or elementary school & 247 & 87.3 & $82.8-90.9$ & 1.083 & 77.1 & $74.8-79.3$ \\
\hline Age group: $0-9$ and $>60$ years & 54 & 12.6 & $9.7-16.3$ & 682 & 29.4 & $27.6-31.3$ \\
\hline Age group: $10-19$ years & 99 & 23.2 & $19.3-27.5$ & 384 & 16.6 & $15.1-18.2$ \\
\hline Age group: 20-39 years & 196 & 45.9 & $41.1-50.8$ & 765 & 33.0 & $31.1-35.0$ \\
\hline Age group: $40-59$ years & 78 & 18.3 & $14.8-22.3$ & 487 & 21.0 & $19.4-22.7$ \\
\hline No. of family members in home: $<5$ peoples & 164 & 56.6 & $50.6-62.3$ & 886 & 62.0 & $59.4-64.5$ \\
\hline No. of family members in home: $>5$ people & 126 & 43.4 & $37.7-49.4$ & 543 & 38.0 & $35.5-40.6$ \\
\hline Not stepping in water when going out from home in winter & 34 & 11.7 & $8.3-16.0$ & 298 & 20.9 & $18.8-23.1$ \\
\hline Stepping in water when going out from home in winter & 256 & 88.3 & $84.0-91.7$ & 1.131 & 79.1 & $76.9-81.2$ \\
\hline Not stepping in water when going out from home in summer & 223 & 76.9 & $71.6-81.6$ & 1.132 & 79.2 & $77.0-81.3$ \\
\hline Stepping in water when going out from home in summer & 67 & 23.1 & $18.4-28.4$ & 297 & 20.8 & $18.7-23.0$ \\
\hline Living in asphalted street & 61 & 21.0 & $16.5-26.2$ & 480 & 33.6 & $31.2-36.1$ \\
\hline Not living in asphalted street & 229 & 79.0 & $73.8-83.5$ & 949 & 66.4 & $63.9-68.8$ \\
\hline Family income: $>1$ minimum monthly salary & 208 & 71.7 & $66.2-76.8$ & 1.166 & 81.6 & $79.5-83.6$ \\
\hline Family income: $<1$ minimum monthly salary & 82 & 28.3 & $23.2-33.8$ & 263 & 18.4 & $16.4-20.5$ \\
\hline Female sex & 175 & 40.3 & $35.7-45.1$ & 1.270 & 54.7 & $52.6-56.7$ \\
\hline Male sex & 259 & 59.7 & $54.9-64.3$ & 1.053 & 45.3 & $43.3-47.4$ \\
\hline Length of time living at locality: $<1$ year & 5 & 1.7 & $0.6-4.0$ & 58 & 4.1 & $3.1-5.3$ \\
\hline Length of time living at locality: $>1$ year & 285 & 98.3 & $96.0-99.4$ & 1.371 & 95.9 & $94.7-96.9$ \\
\hline
\end{tabular}


Table 3 Results of multivariate logistic regression

\begin{tabular}{llcc}
\hline Explanatory variables & OR & $\mathbf{9 5 \%} \mathbf{C l}$ & $\mathbf{p - v a l u e}$ \\
\hline With accumulated water in backyard in winter & 1.40 & $1.06-1.88$ & 0.020 \\
Head of family's schooling: illiterate or elementary school & 1.62 & $1.11-2.42$ & 0.015 \\
Age group: 10-19 years & 2.35 & $1.53-3.65$ & 0.000 \\
Age group: 20-39 years & 2.89 & $1.98-4.28$ & 0.000 \\
Age group: 40-59 years & 2.02 & $1.30-3.16$ & 0.002 \\
Not living in asphalted street & 1.57 & $1.14-2.17$ & 0.006 \\
Family income: $<1$ minimum monthly salary & 1.46 & $1.07-1.98$ & 0.017 \\
Male sex & 1.71 & $1.31-2.24$ & 0.000 \\
\hline
\end{tabular}

AIC 1441.9.

In addition to this regression analysis, analysis models estimating the spatial risk were generated in an attempt to better understand occurrences of schistosomiasis in this area, insomuch as that the environment is an integral and non-dissociable part of the transmission method for this disease. Over the one-year malacological data-gathering period, it was observed that the rainy period directly influenced on the occurrence, density and rate of snail infection. Therefore, it was sought to determine the extent in which this variable influenced the distribution of the breeding sites for B. glabrata and the foci of schistosomiasis transmission. Figure 3 presents a kernel map for the mean parasite load among the individuals who were positive for schistosomiasis per home. On this map, the distribution of breeding sites and transmission foci can be seen. Most of them, except for those located in Merepe III, were within the risk area that presented the parasite load of the cases. This means that although

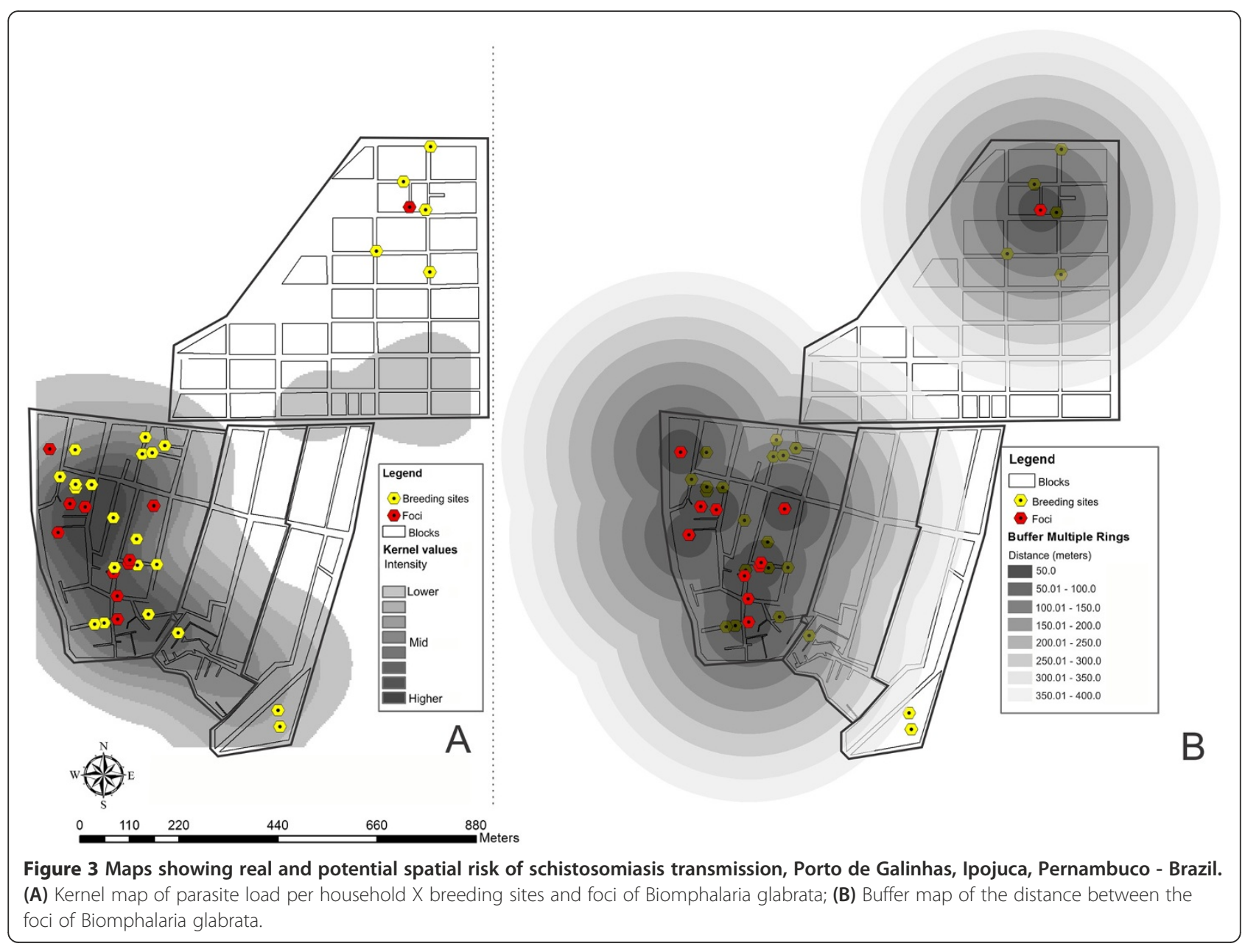


no snails that were positive for $S$. mansoni were found at the breeding sites, these sites were at risk of becoming schistosomiasis transmission foci at any time.

The potential risk of schistosomiasis transmission can be seen in Figure 3(A). This shows that the majority of the breeding sites were in areas in which environmental contamination by the faeces of parasitized individuals existed. The coexistence of foci of transmission in the same region corroborates this observation. One way of better comprehending this potential risk and the influence of the rainfall regime on schistosomiasis transmission can be seen in Figure 3(B). This map provides an estimate of the intensity of exposure of the breeding sites to the risk related to the expansion of the foci, caused by the rainy season in the region. Even if the breeding sites were not originally in contact with environments contaminated by parasitized individuals, they would be vulnerable to the potential risk of becoming foci during rainy periods. This map grades the severity of the risk in 50-meter bands, and it also covers the entire region that becomes flooded during the rainy season. It was observed that at some places the rings converged, thereby indicating that the potential risk was even greater there. So these breeding sites were under the influence of areas of expansion from several transmission foci, i.e. under the influence of several contaminated areas.

The results from the sweep analysis using Bernoulli's method identified 37 clusters, but only one was statistically significant (Figure 4A). This cluster was in Salinas and presented a radius of influence of 117 meters, thus encompassing a total of 207 sampled individuals. Of these, $34.3 \%$ were positive (71 cases) and $65.7 \%$ were negative (136 non-cases) for schistosomiasis. The individuals living in the area covered by this cluster were at 2.2 times greater risk of acquiring schistosomiasis $(\mathrm{RR}=2.21$; p-value $<$ 0.000; 95\% CI). The transmission focus with the highest snail infection rate (breeding site $15 ; 49.1 \%$ ) recorded in this study was within the radius of this cluster (Figure 2). The information obtained from the sweep analysis on the cases made it possible to draw up a final map (Figure 5) that presented the radius of influence of the clusters on the satellite images obtained in 2006 and 2010. This map aimed to present the risk scenario for occurrences of

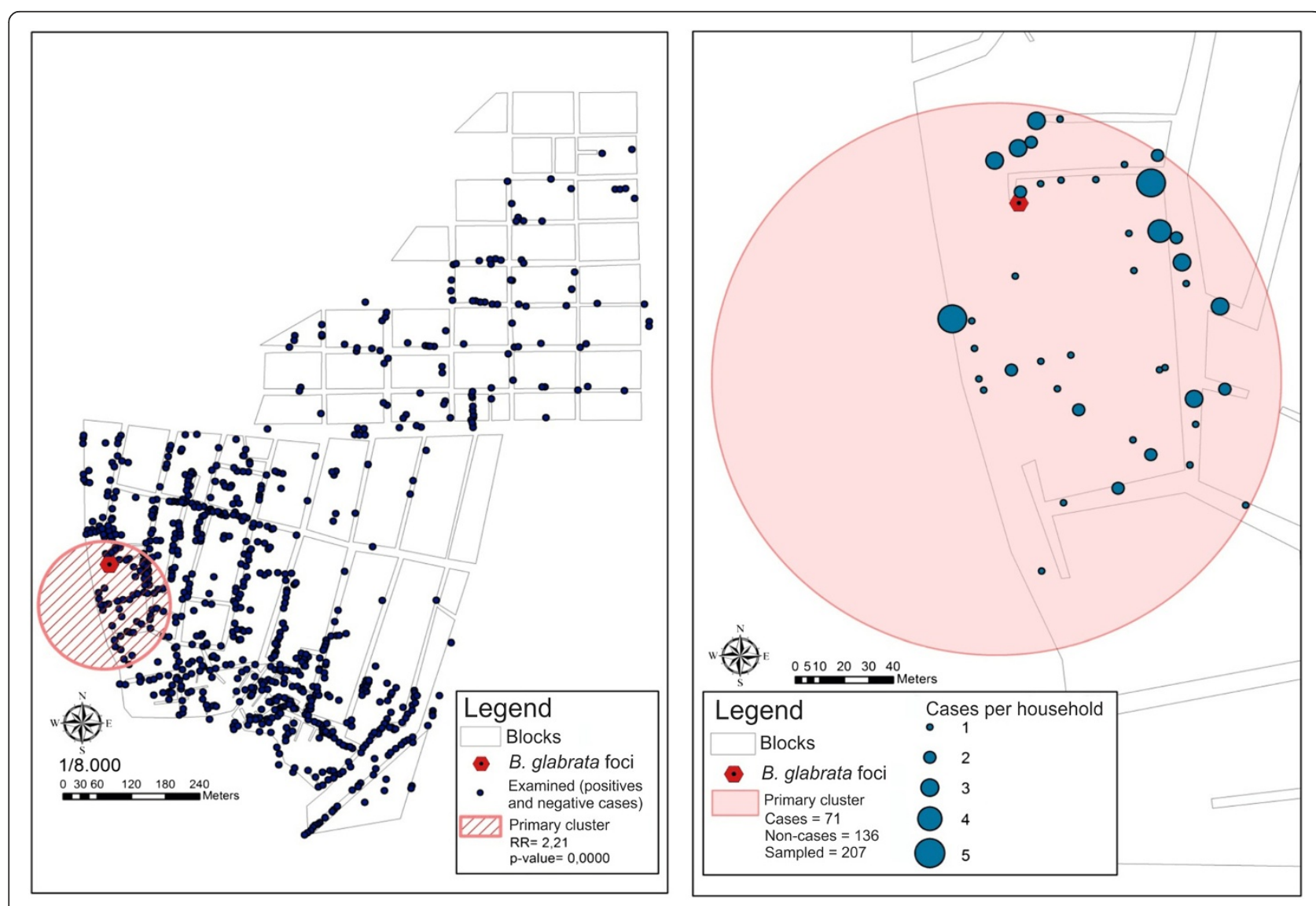

Figure 4 Maps showing spatial sweep analysis on schistosomiasis cases in 2010, Porto de Galinhas, Ipojuca, Pernambuco - Brazil (Bernoulli's method - SaTScan software). 


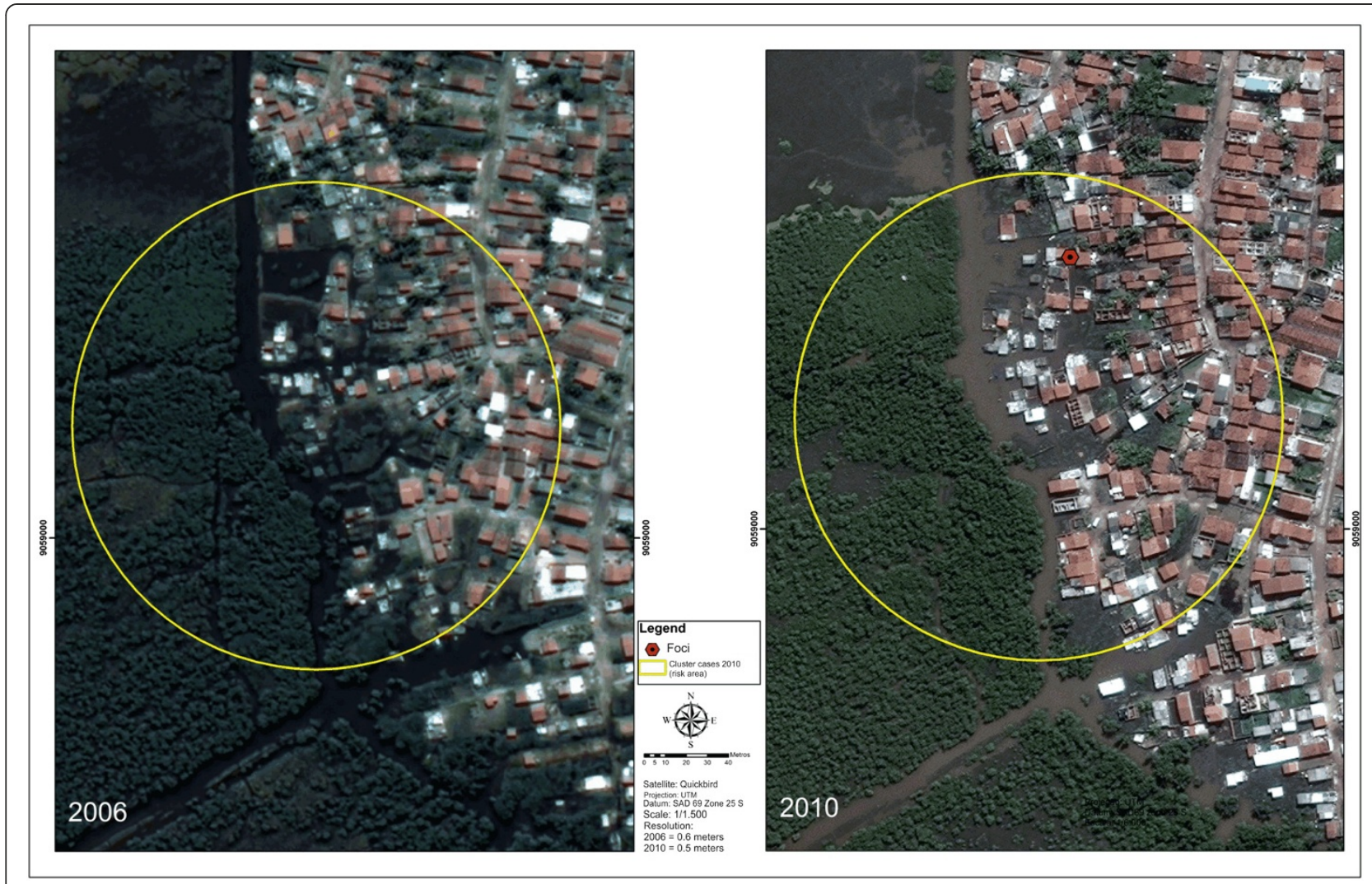

Figure 5 Environmental changes in the identified area of risk in the sweep analysis on schistosomiasis cases 2010, Porto de Galinhas, Ipojuca - Brazil.

schistosomiasis in relation to the process of disorderly urban development. It clearly illustrated the expansion of the built-up areas into the mangrove swamp areas.

It was also observed that the largest focus of transmission registered in 2010 was practically inside the mangrove swamp. This demonstrates that the process of human occupation of land is being accompanied by the expansion of the distribution of foci and breeding sites for Biomphalaria. Figure 5(B) shows the environmental changes that have been occurring in a rapid and uncontrolled manner at this district, with invasion of natural areas that should have been protected.

\section{Discussion}

The biological, environmental and sanitary data gathered, the spatial analyses performed and the testimonies from the interviews with the natives made it possible to portray the current epidemiological scenario for schistosomiasis in Porto de Galinhas. The district of Salinas, which contained most of the foci of schistosomiasis transmission, is the poorest and most heavily populated district of Porto de Galinhas. It has poor basic sanitation and environmental conditions, with sewage outflow in open ditches and unpaved streets without any rainwater drainage system. These characteristics provide ideal conditions for maintaining mollusc breeding sites. In association with these factors, proximity to the mangrove swamp region makes this region vulnerable to periodic flooding caused by overflowing of the Ipojuca river, which flows around the locality. The floods carry the faecal material (exposed on the streets) and the infected snails to other localities, and this favours the appearance of new foci of the disease and exposes residents or vacationers in other districts.

Figure 3 simulates a flood and demonstrates that the rainy period has a large influence on the dynamics of schistosomiasis transmission in Porto de Galinhas. The figure shows that Salinas is the district at the greatest risk of schistosomiasis transmission, taking into consideration the chances of contact with the foci. This can be seen from the prevalence survey, in which Salinas presented a rate of $20.6 \%$, which was the highest rate among all the localities (Table 1). Socó and Pantanal presented the second and third highest prevalence, respectively, and although these localities did not have any confirmed transmission foci, they were suitable to the influence of expansion of the areas at risk caused by floods during the rainy periods.

Young male adults were the most affected individuals by schistosomiasis, probably because they were more exposed to the vector foci located on the streets and in the 
backyards of people's homes. Their contact can be highlighted as accidental, involuntary and inevitable, insomuch as that they needed to cross through these environments in order to carry out their social and labour activities. Another reason that may explain the greatest occurrence of this parasitosis among men is the fact that men tend to seek healthcare services less often than women, even if symptoms are present, which makes it difficult to diagnose and treat the disease [33].

The interviews conducted among the population of Porto de Galinhas made it possible to identify the socioeconomic, behavioural and environmental risk factors that are predictive of the risk of schistosomiasis occurrences. Among the list of variables subjected to multivariate logistic regression, 'accumulation of water in the backyard' was the one that presented the lowest risk $(\mathrm{OR}=1.40 ; 95 \% \mathrm{CI}=1.06$ - 1.88), despite being a frequent and important environmental characteristic regarding the transmission of this disease in Porto de Galinhas. Low schooling level presented by the head of the family and low family income were risk factors for the condition of becoming ill. It is known that these factors influence directly on the family's quality of life [7] and that they indicate poor housing, dietary and health conditions. These factors are directly related to schistosomiasis, considering that this is a disease that affects needy and neglected populations. In Porto de Galinhas, the probability for young adults to contract the disease was almost three times higher than the ones that the reference age group (children and elderly people) may have. Since the young adults were constantly moving around, they were suitable to a higher risk of contact with foci of schistosomiasis transmission.

One significant environmental variable in the predictive model for schistosomiasis occurrences was 'absence of asphalted street'. This factor is directly related to occurrences of breeding sites for B. glabrata, which require earth and water. Even if snails are found in the gutters and puddles of asphalted surfaces, they do not resist the desiccation that takes place in these environments, because the asphalt makes the molluscs' process of 'aestivation' impossible, and consequently impedes their survival during periods of drought. The district of Salinas, which has few paved streets, is vulnerable to the presence of breeding sites and maintenance of cases.

The district of Salinas was the only one to present a statistically significant cluster of occurrences of cases, with a radius of influence of 117 meters, in which the risk of contracting the disease would be 2.2 times higher for the individuals living there (Figure 4). The cases identified in the mangrove swamp area that had suffered the impact of invasions of natural environments and was conducive to flooding that kept the plots of land underwater (Figure 5B) can be highlighted. The population living there was exposed to a higher risk of infection. This figure particularly highlights the greatest impact of the disease on peripheral areas, as the disease affects poor individuals living in invaded areas of the natural environment, without any sanitary infrastructure. The process of expansion and maintenance of schistosomiasis is induced by the way in which people have occupied peripheral and marginalized spaces in Porto de Galinhas.

\section{Conclusion}

Based on the resulting information of this study, the predictive model for schistosomiasis transmission in the coastal area of Porto de Galinhas can be considered for showing that the epidemiological dimensions of this disease are significant and severe, within the scenario of schistosomiasis in Pernambuco. The analysis on the parasito logical aspects of the transmission cycle shows that this locality is a habitat for the vector snail which has the greatest biological potential for infection. B. glabrata is considered to be an efficient host, since it has high resistance to $S$. mansoni infection and is capable of releasing ten times more cercariae (the larvae that infect humans) than B. straminea [34]. Moreover, the identified risk factors in the predictive model make it clear that the environmental and social conditions influence on schistoso miasis occurrences. This constitutes a serious epidemiological scenario, in which the neediest population has been gathered throughout peripheral areas without infrastructure, and thereby destroying natural environments and establishing suitable conditions for maintaining the transmission cycle of this endemic disease in new areas, such as the case in Porto de Galinhas.

There is an urgent need for the public authorities to take measures to ensure that Porto de Galinhas to continue its development as an important tourist centre, by eliminating the deleterious effects of diseases such as schistosomiasis. Such diseases not only have repercussions on health and socioenvironmental organization at the locality, but also may be frustrating the expectations of vacationers and tourists who head there in order to enjoy the natural beauty that this place still offers.

\section{Abbreviations}

B. glabrata: Biomphalaria glabrata; B. straminea: Biomphalaria straminea; EPG: Eggs per gram of faeces; CPqAM: Aggeu Magalhães Research Center.

\section{Competing interests}

The authors declare that they have no competing interests.

\section{Authors' contributions}

ECSG: Conception of the project; data gathering, analysis and interpretation; writing the manuscript; and important critical review of the intellectual content. OBLN: Data gathering at the fieldwork stages and spatial analysis. FJMOJ: Methodology and statistical analysis on the data. JVC: Data gathering at the fieldwork stages. RSS: Conception of the project, statistical and spatial analysis of the data. CSB: Conception and coordination of the project, critical review of the manuscript and final approval of the version to be published. All authors read and approved the final manuscript. 


\section{Authors' information}

ECSG: PhD Public Health and MSc in Animal Biology - Professor of parasitology at Universidade Feraral de Pernambuco - Brazil.

OBLN: Public Health Master's student at Centro de Pesquisas Aggeu

Magalhães - Fiocruz - PE - Brazil.

FJMOJ: Public Health Master's student at Centro de Pesquisas Aggeu

Magalhães - Fiocruz - PE - Brazil.

JVC: Public Health Master's student at Universidade Federal de Pernambuco - Brazil.

RSS: PhD Public Health and MSc Zoology - Head researcher of the department of endemic diseases - ENSP - Fiocruz, RJ - Brazil.

CSB: PhD Public Health and MSc in Biological Sciences - Head researcher of the department of parasitology and Coordinator of the Schistosomiasis Laboratory - CPqAM- Fiocruz - PE - Brazil.

\section{Acknowledgements}

We acknowledge the Schistosomiasis Reference Service and Laboratory CpqAM - Fiocruz and the entire team of technicians who have worked to the malacological and parasitological data survey of this search.

\section{Funding}

This project was funded by CNPq (Conselho Nacional de Desenvolvimento Científico e Tecnológico) - Brazil.

\section{Author details}

'Laboratory of Parasitology, Vitoria Academic Center, Federal University of Pernambuco, Recife, Pernambuco, Brazil. ${ }^{2}$ Schistosomiasis Laboratory and Reference Service, Department of Parasitology, Aggeu Magalhães Research Center, Fiocruz, Recife, Pernambuco, Brazil. ${ }^{3}$ Department of Public Health, Aggeu Magalhães Research Center, Fiocruz, Recife, Pernambuco, Brazil. ${ }^{4}$ Departmant of Endemic Diseases, National School of Public Health, Fiocruz, Rio de Janeiro, Brazil.

Received: 19 March 2013 Accepted: 14 February 2014

Published: 23 February 2014

\section{References}

1. Barbosa CS, Silva CB, Barbosa FS: Esquistossomose: Reprodução e Expansão da Endemia no Estado de Pernambuco no Brasil. Rev Saude Publica 1996, 30(6):609-616.

2. Barbosa CS, Pieri O, Barbosa FS: Ecoepidemiologia da Esquistossomose urbana na llha de Itamaracá. Rev Saude Publica 2000, 34(4):337-341.

3. Kloos H, Correa-Oliveira R, Reis DC, Rodrigues EW, Monteiro LAS, Gazzinelli $A$ : The role of population movement in the epidemiology and control of schistosomiasis in Brazil: a preliminary typology of population movement. Mem Inst Oswaldo Cruz 2010, 105(4):578-586.

4. Bundy DAP, Blumenthal U: Human behaviour and the epidemiology of helminth infection. In Parasitism and Host Behaviour. Edited by Barnard C, Behnke JM. London: Taylor \& Francis; 1990:264-289.

5. Brooker S: Spacial epidemiology of human schistosomiasis in Africa: risk models, transmission dynamic and control. Trop Med Int Health 2007, 101:1-8.

6. Paredes H, Souza-Santos R, Resendes APC, Souza MAA, Albuquerque J, Bocanegra S, Gomes ECS, Barbosa CS: Spatial pattern, water use and risk level associated with the transmission of schistosomiasis on the north coast of Pernambuco, Brazil. Cad Saúde Pública 2010, 26:1013-1023.

7. Ximenes R, Southgate B, Smith PG, Guimarães-Neto L: Socioeconomic determinants schistosomiasis in an urban area in the Northeast of Brazil. Rev Panam Salud Publica 2003, 14(6):409-421.

8. Silva PB, Pieri OS, Travassos A, Florencio L., Barbosa CS: Aspectos físico-químicos e biológicos relacionados a ocorrência de Biomphalaria glabrata em focos litorâneos de esquistossomose em Pernambuco. Quim Nova 2006, 29:901-906.

9. Gazzinelli A, Velasquez-Melendez G, Crawford SB, LoVerde PT, CorreaOliveira R, Kloos H: Socioeconomic determinants of schistosomiasis in a poor rural area in Brazil. Acta Trop 2006, 99:260-271.

10. Coura-Filho P: Uso do paradigma de risco para esquistossomose em áreas endêmicas do Brasil. Cad Saúde Pública 1994, 10(4):464-472.

11. Carvalho MS, Pina MF, Santos SM: Conceitos básicos de sistemas de informação geográfica e cartografia aplicados à saúde. Brasília: OPAS - MS; 2000.

12. Yang GJ, Vounatsou P, Zhou XN, Tanner M, Utzinger J: A Bayesian-based approach for spatio-temporal modeling of county level prevalence of Schistosoma japonicum infection in Jiangsu province, China. Int J Parasitol 2005, 35:155-162.
13. Cross ER, Bailey RC: Prediction of areas endemic for schistosomiasis through use of discriminant analysis of environmental data. Mil Med 1984, 149:28-30.

14. Cross ER, Bailey RC: Predicting areas endemic for schistosomiasis using weather variables and a Landsat data base. Mil Med 1984, 149:542-543.

15. Brooker S, Hay SI, Issae W, Hall A, Kihamia CM, Lwambo NJS, Wint W, Rogers DJ, Bundy DAP: Predicting the distribution of urinary schistosomiasis in Tanzania using satellite sensor data. Trop Med Int Health 2001, 6:998-1007.

16. Kulldorff M, Nagarwall A: Spatial disease clusters: detection and inference. Stat Med 1995, 14:799-810.

17. Cardim LL, Ferraudo AS, Pacheco STA, Reis RB, Silva MMN, Carneiro DDMT, Bavia ME: Analises espaciais da identificação das áreas de risco para a esquistossomose mansônica no município de Lauro de Freitas, Bahia, Brasil. Cad Saúde Pública 2011, 27(5):899-908.

18. Coleman M, Mabuza AM, Kok G, Coetzee M, Durrheim DN: Using the SaTScan method to detect local malaria clusters for guiding malaria control programmes. Malar J 2009, 8:68.

19. Odoi A, Martin SW, Michel P, Middleton D, Holt J, Wilson J: Investigation of clusters of giardiasis using GIS and spatial scan statistic. Int J Health Geogr 2004, 3:11.

20. Brasil. Ministério da Saúde: Guia de Vigilância Epidemiológica. In Secretaria de Vigilância em Saúde. 7th edition. Brasilia: Secretaria de Vigilância em Saúde, "Departamento de Vigilância Epidemiológica"; 2010.

21. Lambertucci JR: Acute schistosomiasis mansoni: revisited and reconsidered. Mem Inst Oswaldo Cruz 2010, 105(4):422-435.

22. Katz N, Peixoto SV: Análise crítica da estimativa do número de portadores de esquistossomose no Brasil. Rev Soc Bras Med Trop 2000, 33:303-308.

23. Barbosa CS, Domingues ALC, Abath F, Montenegro SML, Guida U, Carneiro J, Tabosa B, Moraes CNL, Spinelli V: Epidemia de Esquistossomose Aguda na Praia de Porto de Galinhas, Pernambuco, Brasil. Cad. Saúde Pública 2001, 17(3):725-728.

24. Barbosa CS, Montenegro SML, Abath FGC, Domingues ALC: Specific situations related to acute schistosomiasis in Pernambuco, Brazil. Mem. Inst.Oswaldo Cruz 2001, 96:169-172.

25. Barbosa CS, Araújo KC, Antunes L, Favre T, Pieri OS: Spacial distribution of schistosoma mansoni foci in Itamaracá Island, Pernambuco, Brazil. Mem. Inst.Oswaldo Cruz 2004, 99:79-83.

26. Barbosa CS, Araújo KC, Sevilha MAA, Melo F, Gomes ECS, Souza-Santos R: Current epidemiological status of schistosomiasis in the state of Pernambuco, Brazil. Mem. Inst. Oswaldo Cruz 2010, 105(4):549-554.

27. Araújo KCGM, Resendes APC, Souza-Santos R, Silveira Júnior JC, Barbosa CS Análise espacial dos focos de Biomphalaria glabrata e de casos humanos de esquistossomose mansônica em Porto de Galinhas, Pernambuco, Brasil, no ano 2000. Cad. Saúde Pública 2007, 23(2):409-418.

28. Barbosa CS, Leal Neto OB, Gomes ECS, Araújo KCGM, Domingues ALC: The endemisation of schistosomiasis in Porto de Galinhas, Pernambuco, Brazil, 10 years after the first epidemic outbreak. Mem Inst Oswaldo Cruz 2011, 106:878-883.

29. Gomes ECS, Leal Neto OB, Albuquerque J, Silva HP, Barbosa CS: Schistosomiasis transmission and environmental change: a spatio-temporal analysis in Porto de Galinhas, Pernambuco - Brazil. Int J Health Geogr 2012, 11:51.

30. Kuntz ER: Effect of light and temperature on shedding of Schistosoma mansoni cercarie. Nav Med Res Inst 1946, 7:16.

31. Coutinho JO: Índices de infestação natural dos planorbídeos pelas cercárias do Schistosoma mansoni na cidade do Salvador- Bahia. Anais da Faculdade de Medicina de São Paulo 1950, 25:29-53.

32. Katz N, Chaves A, Pelegrino J: A simple device for quantitative stool thick smeart technique in schistosomiasis mansoni. Rev. Inst. Med. Trop 1972, 14:371-373.

33. Gomes R, Nascimento EF, Araújo FC: Por que os homens buscam menos os serviços de saúde do que as mulheres? As explicações de homens com baixa escolaridade e homens com ensino superior. Cad Saúde Pública 2007, 23(3):565-574.

34. Neves DP, Melo AL, Linardi PM, Vitor RWA: Parasitologia Humana. 11th edition. São Paulo: Atheneu; 2005:494.

doi:10.1186/1471-2334-14-101

Cite this article as: de Souza Gomes et al:: Risk analysis for occurrences of schistosomiasis in the coastal area of Porto de Galinhas, Pernambuco, Brazil. BMC Infectious Diseases 2014 14:101. 